\title{
Entre o riso e a ruína: humor, romance e regionalismo em José Lins do Rego
}

Juliana Santini

RESUMO: Este trabalho propõe uma análise do romance Fogo morto, publicado em 1943 por José Lins do Rego, considerando de que modo o humor atua como instrumento que particulariza a narrativa no conjunto da ficção do autor. O texto propõe que o humor articula crítica e análise psicológica na definição de parte do romance regionalista da "geração de 30" no modernismo brasileiro.

PALAVRAS-CHAVE: regionalismo brasileiro; romance; humor

\begin{abstract}
This work proposes an analysis of the novel Fogo morto, published in 1943 by José Lins do Rego, considering the way by which humour operates as an instrument that particularizes this narrative in the fiction of its author. The proposed question is that humour articulates critical and psychological analysis in the definition of regionalist novel of "Generation of Thirty" in Brazilian Modernism.
\end{abstract}

KEYWORDS: Brazilian regionalism; novel; humour 


\begin{abstract}
A literatura, com ser ficção, resiste à mentira. É nesse horizonte que o espaço da literatura, considerado em geral como o lugar da fantasia, pode ser o lugar da verdade mais exigente.
\end{abstract}

Alfredo Bosi

Nas interpretações críticas acerca do regionalismo literário brasileiro, é recorrente a ideia de que a transformação do conto sertanejo do início do século xx para o romance regionalista da segunda geração do modernismo envolve, em maior ou menor grau, uma tomada de consciência crítica que desloca o tom caricaturesco do personagem-tipo pré-modernista e lhe dá profundidade em uma estrutura romanesca que, na década de 30, atende a uma perspectiva ideológica que determina a própria estrutura. Considerando a heterogeneidade das produções envolvidas pelo designativo "romance regionalista de 30 ", é importante, porém, que se dê atenção aos elementos e particularidades que, no interior desse conjunto, delineiam poéticas individuais.

À luz desse pressuposto, a ficção de José Lins do Rego pode ser tomada em uma análise que considera o lugar do humor no romance Fogo morto, de 1943, privilegiando a relação entre a forma humorística e o regionalismo do autor, que não deixa definir parte do paradigma regionalista em questão. Nesse caso, a hipótese é que o humor serve à representação da decadência a que estão submetidos os personagens da narrativa, todos ligados à falência da estrutura produtiva que os encaixava antes da modernização dos meios de produção do açúcar. A consonância entre a forma do romance e a perspectiva trágica do humor coloca em evidência a cisão desses personagens entre presente em passado, o que, em última instância, determina a loucura que os constitui.

\title{
PROJETO IDEOLÓGICO COMO REAÇÃO ESTÉTICA: O MANIFESTO REGIONALISTA
}

É fato que a Semana de Arte Moderna representou uma guinada na literatura e nas artes plásticas brasileiras, especialmente no modo de avaliação do dado local, tomado, sobretudo, como meio de recuperação de um passado a ser redescoberto pelo olhar modernista, que erige a tradição sob os traços da novidade da 
forma, ${ }^{1}$ que foge da figuratividade plástica e da rigidez da linguagem literária, ao mesmo tempo em que se volta para a redescoberta da nação. Por outro lado, essa proposta estética do grupo modernista inicial não encontrou resposta unânime nas diferentes regiões do país e permaneceu atrelada à esfera do desenvolvimento econômico e cultural de São Paulo e Rio de Janeiro, o que impulsionou a reação do grupo nordestino reunido em torno do pensamento de Gilberto Freyre, no Centro Regionalista do Nordeste, a partir de 1923.

É de base sociológica a motivação do Grupo Regionalista e, articulada à tentativa de fixação dos costumes e tradições populares do Nordeste, desde o início não deixou de registrar a procura por uma forma de representação literária da realidade regional e de sua multiplicidade cultural. As propostas do grupo encontram respaldo, ainda, em um aspecto da história econômica da região: o Nordeste havia perdido o domínio sobre o capital nacional desde o início da transformação dos meios de produção e do desenvolvimento e urbanização da região Sudeste, de modo que à reivindicação de relevância no quadro cultural do país corresponde, também, uma espécie de resposta à decadência econômica e ao esfacelamento das estruturas sociais historicamente erigidas sob o cultivo da cana-de-açúcar.

Subjaz à visão de diversidade cultural, fundamentadora do Manifesto regionalista, a mesma concepção federalista de um território nacional retalhado em regiões que influenciou parte da literatura produzida ao longo do pré-modernismo. O papel desempenhado pelo vínculo entre a ideia de federalismo e o intento de captação artística da diversidade é avaliado por Gilberto Freyre vinte e cinco anos após a realização do Congresso Regionalista do Nordeste, em discurso que coloca em cena os alicerces que sustentaram o movimento nordestino:

O Regionalismo - senão criação pura no que assumiu de complexo em suas combinações novas de ideias porventura velhas, sistematização brasileira, realizada por um grupo de homens do Recife, não só de novos critérios regionais de vida, de estudo e de arte como de vagas e dispersas tendências para-regionalistas já antigas no Brasil mas quase deformadas em aventuras de "pitoresco" ou "cor local", está, de modo geral, para a cultura brasileira, que libertou dos excessos de centralização, como o Federalismo está,

1. Santiago, Silviano. "A permanência do discurso da tradição no modernismo". In: . Nas malhas da letra. Rio de Janeiro: Rocco, 2002, pp. 108-44. 
em particular, para a vida política do país, descentralizada, embora sob alguns aspectos erradamente descentralizada, pelos triunfadores de $89 .^{2}$

José Aderaldo Castello, em conhecido estudo, ${ }^{3}$ analisa as relações entre o regionalismo nordestino e as propostas dos intelectuais do primeiro momento do modernismo, apontando para as disparidades iniciais entre os dois grupos e, principalmente, para o que se pode identificar como pontos de consonância entre ambos. Interessa, nesse sentido, a maneira como o crítico detecta não apenas a articulação entre planos artístico-literários, mas especialmente a dimensão modernista dessa literatura regionalista, assentada na conservação do passado e na depuração de uma forma literária - o romance como modo de expressão adequado ao objeto que o definiria.

Entra em cena, aqui, o dinamismo entre os dois projetos apontados por João Luiz Lafetá na constituição do modernismo brasileiro, essenciais para a compreensão da natureza da narrativa regionalista, quando considerada do ponto de vista de um diálogo com o grupo de 22: "[...] não podemos dizer que haja uma mudança radical no corpo de doutrinas do modernismo; da consciência otimista e anarquista dos anos 1920 à pré-consciência do subdesenvolvimento há principalmente uma mudança de ênfase". ${ }^{4}$ Tendo como verdadeira a proposição de que o ponto de vista não altera o objeto observado, há que se notar que os germes dessa "pré-consciência" - retomada pelo crítico dos estudos de Antonio Candido ${ }^{5}$ - entraram em discussão praticamente de modo simultâneo ao "projeto estético" da Semana de Arte Moderna, evidenciando a filiação entre pesquisa estética e preocupação sociológica no processo histórico de formação e afirmação da literatura modernista no Brasil.

É nessa ambivalência de um movimento que se colocava além do modernismo paulista, como forma de avultar a importância da cultura nordestina e de buscar um modo de expressão estética adequado a essas particularidades, que se constitui o binômio modernismo/tradicionalismo, espécie de síntese de propostas artísticas que

2. FREYRE, Gilberto. Manifesto regionalista de 1926. Departamento de Imprensa Nacional; Serviço de Educação, 1955.

3. Castello, José. Aderaldo. José Lins do Rego: modernismo e regionalismo. São Paulo: Edart, 1961.

4. Lafetá, João Luiz. 1930: a crítica e o modernismo. 2. ed. São Paulo: Duas Cidades; Ed. 34, 20oo, p. 30 (grifos do autor).

5. CAndido, Antonio. A educação pela noite e outros ensaios. 3. ed. São Paulo: Ática, 2000. 
congregaram em torno de si a pesquisa sociológica, a crítica social e a consciência da falência da sociedade e do indivíduo. Sobre o tradicionalismo fundamentaram-se não apenas a pesquisa e a tentativa de revitalização de costumes locais, mas também a consciência em relação ao hiato que se desenhava entre a modernização dos meios de produção e as transformações socioeconômicas que daí se originavam, de um lado, e o esmagamento da dimensão humana do espaço, de outro.

O regionalismo coloca-se entre uma e outra proposta, entretecido pelo fio da memória, revitalização do passado que se faz presente por meio do ato da escritura. Tomada sob esse ponto de vista, a prosa regionalista de então congrega em suas páginas um olhar sociológico - que pincela as cores do sertão e analisa criticamente a condição daqueles que o habitam - atrelado ao avultamento de tradições que se articulam ao tecido narrativo e ao enfoque, muitas vezes de aguda percepção psicológica, do homem desajustado aos esquadros que se desenham com a modernização e o progresso. Desse último traço - o mergulho no drama do homem que vive o esfacelamento da sociedade rural patriarcal - deriva o universalismo de romances como São Bernardo, de Graciliano Ramos, e Fogo morto, de José Lins do Rego, em que o coletivo e o individual se fundem no mesmo relato de falência.

A articulação entre regionalismo e universalismo, de um lado, e entre crítica e pesquisa sociológica, de outro, fundamenta um paradigma literário mais complexo e menos superficial, concretizando a subtração do exotismo e do pitoresco que tingiam a literatura regionalista nos primeiros anos do século xx. Essa transformação justifica a postura de Nelson Werneck Sodré ${ }^{6}$ que, ao analisar a questão, aponta o Jeca Tatu de Monteiro Lobato como o fim do regionalismo tradicional por representar em seus traços, por meio da caricatura, uma disparidade entre a forma e o conteúdo, em que a exterioridade do tipo suprimia o drama interior do personagem. Sob esse aspecto, a forma romanesca serviria à anulação dessa disparidade ao plasmar forma e conteúdo em uma estrutura menos superficial - como era a caricatura na composição de personagens-tipo —, de modo que crítica e análise psicológica se entrecruzariam em um mesmo ponto do tecido narrativo.

A importância das propostas do grupo de 1923 para que uma nova situação se consolidasse e o regionalismo passasse a assumir esse novo significado, agora menos localista e tipificador, mostra-se mais clara na medida em que se considera o papel

6. SODRÉ, Nelson Werneck. História da literatura brasileira: seus fundamentos econômicos. 8. ed. Rio de Janeiro: José Olympio, 1988. 
fundamental dos estudos sociológicos de Gilberto Freyre, tanto no adensamento da perspectiva crítica assumida pelo romance, quanto na centralidade aferida ao envolvimento com a cultura brasileira, valorizada e reanimada por meio de um processo memorialista de escritura, em que o contato do intelectual com a tradição popular "[...] não deve ser perdido em nenhuma atividade regional".'

\section{NARRATIVA E DECADÊNCIA}

Essa nova perspectiva do regionalismo encontrou, na obra de José Lins do Rego, espaço para se consolidar enquanto tradicionalismo, universalismo e memorialismo. A inexorabilidade do tempo e a falibilidade do homem aparecem, nos romances do escritor paraibano, por meio de um entrecruzar de tempos que se projetam na memória de personagens cindidos entre o presente e o passado, o apogeu e a decadência. Fogo morto, espécie de continuação e síntese do Ciclo da cana-de-açúcar, mostra-se como um ponto de confluência dos traços essenciais de um regionalismo de denúncia social e pesquisa humana. À feição sociopolítica da decadência liga-se a dimensão psicológica do habitante do sertão, analisada em diferentes prismas na medida em que a narrativa se constrói pelo enfoque de personagens que pertencem a esferas distintas da sociedade, todas elas desestabilizadas pelo progresso não planificado.

A inclinação trágica do declínio estrutura-se, no romance, a partir da segmentação de três eixos narrativos, individualizados nos personagens que servem de escopo a cada um dos três capítulos da obra. A cada eixo narrativo corresponde uma dimensão subjetiva do tempo, tornada coletiva na medida em que evoca a falência do personagem e do segmento social que representa: as trajetórias de José Amaro, Lula de Holanda e Vitorino Carneiro da Cunha correm em paralelo à história de criação, apogeu e decadência do engenho Santa Fé, propriedade que não se adequou aos novos modos de produção e permaneceu estagnada, espaço presente que vive a dimensão do tempo de outrora.

Todos ligados ao desenvolvimento do engenho Santa Fé, esses personagens têm suas vidas envolvidas em uma engrenagem de anacronismo e decadência, de modo que a propriedade em ruínas que dá título ao romance mostra-se como uma metáfora

7. Freyre, Gilberto. Manifesto regionalista de 1926. Departamento de Imprensa Nacional; Serviço de Educação, 1955, p. 48. 
da ausência de possibilidades de mudança e, simultaneamente, como metonímia da inadequação dos modos de produção antigos diante da industrialização, projetandose, ainda, para o aspecto social que daí se desprende. O engenho Santa Fé, que fora fundado pelo capitão Tomás, teve um desenvolvimento meteórico e, dois anos após sua fundação, que ocorreu em 1848, já era respeitado como uma das propriedades mais produtivas da região, a despeito de sua pequena extensão. A disciplina e o trabalho do proprietário fizeram do engenho um espaço de prosperidade, marcada simbolicamente pela chegada do piano de Amélia, em 1850, ano em que se fez a última pintura na casagrande, momento áureo do cultivo da cana e beneficiamento do açúcar.

Quarenta anos depois de sua fundação, no momento em que a escravatura foi abolida, o velho engenho já tem como consolidada a condição de "fogo morto", sem produzir e gerar renda capaz de garantir a subsistência de seus proprietários, que assistem à decadência das terras e ao escoamento de toda a herança deixada pelo velho Tomás. Essa trajetória do Santa Fé e sua relação com a falência social e psicológica dos personagens que estruturam a narrativa articulam-se temporalmente com o percurso histórico do açúcar no Nordeste do Brasil. O ano de 1875 marca o início de medidas governamentais concretas para a modernização da produção de açúcar na região, principiando a substituição dos banguês por usinas. Na virada do século, em Pernambuco, as usinas já os superam em número e volume de produção, e essa reestruturação do sistema produtivo começa a gerar uma significativa transformação no perfil socioeconômico da região, pois os antigos engenhos paulatinamente perdem sua função e se transformam em fábricas de rapaduras ou em simples fornecedores de matéria-prima às usinas. ${ }^{8}$

Essa mudança afeta, ainda, a estrutura da pirâmide social estabelecida a partir de classes ligadas à produção do açúcar. Com a modernização das usinas, os antigos senhores de engenho passaram à categoria de pequenos proprietários de cana-de-açúcar, sujeitos aos novos senhores na medida em que se tornaram seus fornecedores, ocupando o mesmo posto que os meeiros, que utilizavam terras arrendadas para a produção da cana. É importante notar que essa classe de fornecedores, situada entre o trabalhador braçal - trabalhadores livres e ex-escravos - e o usineiro, seria absorvida pelo progresso das usinas, já que estas se sustentariam a partir de safra própria, dispensando a intermediação dos pequenos produtores, agora sem lugar na antiga organização social e incapazes de se encaixar em sua nova configuração.

8. CArone, Edgard. A República Velha (instituições e classes sociais). São Paulo: Difel, 1970. 
O velho engenho de Lula não acompanha esse desenvolvimento, e o processo de transformação dos banguês em usinas e seu declínio determinam a decadência dos três personagens que sustentam a narrativa:

A carruagem rompia as estradas com o povo mais triste da várzea indo para a missa do Pilar, para as novenas, arrastada por cavalos que não eram mais nem a sombra dos dois ruços do capitão Tomás. A barba de seu Lula era toda branca, e as safras de açúcar e de algodão minguavam de ano para ano. As várzeas cobriam-se de grama, de mata-pasto, os altos cresciam em capoeira. Seu Lula, porém, não devia, não tomava dinheiro emprestado. Todas as aparências de senhor de engenho eram mantidas com dignidade. Diziam que todos os anos ia ele ao Recife trocar as moedas de ouro que o velho Tomás deixara enterradas. A cozinha da casa-grande só tinha uma negra para cozinhar. E enquanto na várzea não havia mais engenho de bestas, o Santa Fé continua com as suas almanjarras. Não botava máquina a vapor. ${ }^{9}$

A resistência ao progresso e a tentativa de manter a imagem de imponência, poder e prosperidade de outrora em uma nova configuração político-econômica e social criam, portanto, um atrito entre presente e passado - e, em última instância, entre realidade e imaginação - , de modo que é o fantasma do passado que rege os escombros do presente e institui a loucura como meio e fim dos personagens da narrativa.

A loucura sonda o personagem José Amaro tanto na figura da filha Marta quanto no esfacelamento de qualquer possibilidade de existência de uma identidade individual que o defina. Seleiro que já não tem no ofício o mesmo sucesso de outrora - os meios de produção deslocaram para a cidade os atrativos do comércio e, em consequência, a atividade profissional que o constituía como sujeito deixou de existir -, mestre Amaro vive nas terras do Santa Fé, em um ponto da estrada que liga o engenho de Lula ao Santa Rosa, propriedade próspera de José Paulino, até ser expulso pelo capitão por estar ligado ao cangaço e não se julgar obrigado a respeitar a imponência e as ordens do senhor de engenho. É interessante notar que mestre Amaro toma como ponto fundador de suas recordações a imagem do trabalho, o movimento de produção do engenho antigo, agora com o fogo praticamente extinto:

9. Rego, José Lins do. Fogo morto. 47. ed. Rio de Janeiro: José Olympio, 1997, pp. 160-1. 
Cinquenta escravos lavravam a terra do Santa Fé. Tinha uma fortuna em negros, o capitão Tomás. Agora era aquilo que se via, um engenho de duzentos pés, moendo cana, puxado a besta. Toda a alegria do seleiro se pondo como um sol em dia de chuva. Todo ele enroscava-se outra vez, fechava-se em sombras. E a cara dura, os olhos inchados, a tristeza íntima, eram outra vez o mestre José Amaro. ${ }^{10}$

A metáfora da sombra empresta seu significado tanto à tristeza de José Amaro, que acaba por se matar, quanto à loucura do capitão Lula. Homem da cidade, que se casa com a filha de Tomás por interesse, Lula nunca demonstrou empolgação pela administração do engenho do sogro. Assumindo a propriedade após a morte de seu fundador, o capitão veste-se com a imponência e o poder dos anos de apogeu do Santa Fé, mas é incapaz de manter seu funcionamento diante do progresso e das transformações dos modos de produção. Em oposição a José Paulino, dono do engenho Santa Rosa, que se reestrutura para se inserir no novo contexto da industrialização, Lula de Holanda Chacon mergulha na penumbra e adoece, vítima de sucessivas crises convulsivas.

As imagens da decadência crescente de Lula e da amargura de José Amaro contrastam com a silhueta faceira do capitão Vitorino Carneiro da Cunha. Não menos atado à dimensão trágica do tempo, Vitorino, ao contrário dos dois outros personagens, desenvolve uma trajetória em que essa mesma tragicidade se opõe aos contornos criados por sua imaginação. A figura de Vitorino, na verdade, resume uma certa oposição entre realidade e ilusão que traz o cômico para o interior da narrativa, diluindo parte da atmosfera lúgubre de sombra e do "cheiro de morte" que impregna as descrições do narrador.

Sob esse aspecto, o cômico institui-se na medida em que se cria uma figura caricaturesca do velho Vitorino, figura esguia, que acredita ser capaz de mudar a situação marginal do sertanejo por meio da política. Ao mesmo tempo em que traz à tona a problemática do coronelismo, ilustrada pela política e a tentativa de angariar votos para seu candidato, o personagem assume uma dimensão quixotesca ao acreditar em uma imagem de poder que criou para si, traços que destoam da aparência decrépita que compartilha com sua égua, verdadeiro cavalo alazão em suas descrições:

[...] E quando pensava nessas coisas surgiu na estrada o seu compadre Vitorino. Vinha na égua magra, com a cabeça ao tempo, toda raspada. Saltou para uma conversa e estava

10. Id., p. 63. 
vestido como um doutor, de fraque cinzento, com uma fita verde e amarela na lapela. $\mathrm{O}$ mestre José Amaro olhou espantado para a vestimenta esquisita.

- Estou chegando, compadre, do Itambé. O doutor Eduardo tinha um réu para defender e mandou me chamar no Gameleira para ajudá-lo. Lourenço, o meu primo desembargador, me disse: "Olhe, Vitorino, você para ir à barra do tribunal do júri precisa desse fraque”. E me deu este. É roupa feita lá do Mascarenhas, de Recife. Botei o bicho. Então o primo Raul me chamou para um canto para dizer que eu precisava cortar os cabelos. O desgraçado do barbeiro da Lapa tosquiou-me a cabeleira, o jeito que tive foi de raspar tudo. Raul passou-me a navalha na cabeça. Me disseram que era moda no Recife para advogado. Quando cheguei no Itambé o júri já tinha se acabado."

Comicidade que se enovela ao trágico destino dos outros personagens e, ainda, não deixa de se opor à própria condição marginal de Vitorino, revelada ao leitor pelo discurso do narrador onisciente que entretece toda a narrativa, em uma narração entremeada por fios de análise psicológica que, mais do que evidenciar os desníveis entre a realidade em que vive o personagem e aquela criada por ele, sintetiza em um mesmo ponto a derrocada inevitável e a ilusão empreendedora de seu sonho.

Embora dilua, em certa medida, a crueza do trágico que se impõe à condição dos personagens envoltos pela inexorabilidade do fim e atormentados pela inadequação ao presente, o riso que desponta do herói caricaturesco de José Lins do Rego não permanece incólume nesse contexto de decadência e morte. A mesma linha temporal que liga a tríade estruturadora do romance e a une à falibilidade do engenho em ruínas alinhava cômico e trágico, sintetizando um e outro de modo a instituir uma ponte que coloca lado a lado outros pares de contrastes que fundamentam a narrativa: presente e passado, prosperidade e decadência, realidade e ilusão, vida e morte. A dimensão psicológica do tempo que se escoa e mesmo a descontinuidade entre diferentes tempos, marcada pela onisciência narrativa que traz à tona a data de apogeu do Santa Fé - 1850 -, contrastam com a ruína do presente da narrativa e se colocam como ponto de mediação da loucura de Lula de Holanda e da inadequação de José Amaro, determinando, ainda, o ruir dos sentidos de

[...] indivíduos colocados numa linha perigosa, em equilíbrio instável entre o que foram e o que não serão mais, angustiados por essa condição de desequilíbrio que cria tensões

11. Id., pp. 92-3. 
dramáticas, ambientes densamente carregados de tragédia, atmosferas opressivas, em que o irremediável anda solto. ${ }^{12}$

Essa "tensão dramática" a que alude Antonio Candido encontra, no humor, instrumento para se realizar enquanto expressão de contrastes e desajustes. Assim, a imagem de Vitorino Carneiro da Cunha corrobora a mesma insanidade e inadequação de Lula e José Amaro; entretanto, os contornos de seu comportamento hiperbólico afastam a atmosfera de morte que ronda os dois primeiros. Nesse caso, se o risível da caricatura chama a atenção para o que Pirandello ${ }^{13}$ denominaria de "advertência do contrário", escopo da realização cômica, ${ }^{14}$ a constatação de que o personagem encarna "a representação da incompatibilidade do homem diante do mundo e/ou diante de seus pares" ${ }^{15}$ resvala para a reflexão acerca das condições que transformaram esse homem de "coração puro" ${ }^{16}$ em um ingênuo joguete da realidade que o envolve, trazendo para o interior do riso o compadecimento em relação a sua condição.

12. Candido, Antonio. Brigada ligeira e outros escritos. São Paulo: Editora Unesp, 1992, p. 61.

13. Pirandello, Luigi. O humorismo. Tradução de Dion Davi Macedo. São Paulo: Experimento, 1996.

14. Ao lado dos apontamentos sobre a comicidade, Pirandello define a ambivalência do humor: enquanto o cômico adverte acerca do desvio e busca a correção, o humor é definido pelo dramaturgo como o "sentimento do contrário", que se manifesta a partir da tomada de consciência acerca do erro cometido pelo alvo do riso e, no lugar de um riso punitivo, impõe um sentimento de compaixão em relação a esse alvo justamente por se estar diante de uma reflexão que revela, àquele que ri, as condições adversas que conduziram o objeto do riso a uma posição considerada à margem da normalidade. O que Pirandello faz, na verdade, é instituir uma gradação entre o cômico e o humor, colocando o segundo como uma realização que parte do primeiro, mas se transforma, diluindo a zombaria e a derrisão do primeiro e produzindo, em vez de rebaixamento, compaixão. O humor é, portanto, um fenômeno essencialmente híbrido, que depende do entrecruzar de duas esferas colocadas como opostas pela tradição do riso. Cômico e trágico, riso e compaixão, riso e razão, riso e reflexão coexistem, na perspectiva de Pirandello, em um todo de faces múltiplas, que visa menos à punição do que à reflexão. A dimensão punitiva - porque promotora de uma segregação — do cômico mescla-se à profundidade de uma consciência ou de um aprendizado que oferece ao sujeito o reconhecimento de sua incapacidade de resolver seus conflitos exteriores e, sobretudo, aqueles que colocam o homem diante da fragilidade da vida.

15. MarchezAn, Luiz Gonzaga. Fogo morto e O coronel e o lobisomem: duas vertentes de uma poética da loucura na literatura brasileira. In: Marchezan, Luiz Gonzaga; Telarolli, Sylvia. (Orgs.). Cenas literárias: a narrativa em foco. Araraquara: Unesp, FCL, Laboratório Editorial; São Paulo: Cultura Acadêmica, 2002, p. 54.

16. Rego, José Lins do. Fogo morto, cit., p. 243. 
É, portanto, no choque entre a silhueta cômica de Vitorino e toda a tragicidade que se depreende das figuras de Lula e de mestre Amaro, representantes da inadequação do homem a um novo tempo que se inaugura com o progresso, que reside a interferência necessária para a realização do humor, liame em que se entretecem elementos aparentemente díspares. Nesse sentido, a ambivalência do humor torna-se possível na medida em que a tessitura do texto narrativo institui contrastes estruturais que põem lado a lado - justamente para que se revelem as dissonâncias - não apenas tempos diversos, mas maneiras distintas de cada personagem se colocar diante de uma mesma realidade circundante. Enquanto a decadência do engenho Santa Fé representa a falência de todo um sistema produtivo que fora substituído por uma nova ordem econômico-social, a dimensão psicológica da tríade de personagens projeta a feição humana dessa falência, opondo ao progresso os escombros de um passado em ruínas.

\section{ROMANCE, HUMOR, REGIONALISMO}

No ponto em que já se tem um dos fios que unem cômico e trágico à estrutura da narrativa, é momento de considerar de que modo se constitui a relação entre humor e romance, passo necessário à compreensão da natureza do regionalismo de José Lins do Rego. A esse respeito, convém retomar a posição de Alfredo Bosi ${ }^{17}$ acerca da prosa brasileira que se produziu a partir de finais da segunda década do século xx, reflexão que o crítico constrói tendo por base o esquema interpretativo desenvolvido por Lucien Goldmann ${ }^{18}$ em A sociologia do romance, volume em que traça um perfil do romance moderno considerando a estrutura romanesca como representação de uma determinada estrutura social, forma em que um herói problemático entra em tensão com a degradação de valores que a sociedade, também degradada, não consegue sustentar. ${ }^{19}$

Transpondo o esquema para o contexto literário brasileiro, Alfredo Bosi aponta para a classificação do romance produzido a partir de 30 em quatro tendências

17. Bosi, Alfredo. História concisa da literatura brasileira. 35. ed. São Paulo: Cultrix, 1997.

18. Goldmann, Lucien. A sociologia do romance. Tradução de Álvaro Cabral. 3. ed. Rio de Janeiro: Paz e Terra, 1990.

19. Cf. também Lukács, Georg. A teoria do romance: um ensaio histórico-filosófico sobre as formas da grande épica. Tradução de José Marcos Mariani de Macedo. 2. ed. São Paulo: Ed. 34; Duas Cidades, 2009. 
principais: "romances de tensão mínima", "romances de tensão crítica", "romances de tensão interiorizada" e "romances de tensão transfigurada". É fato que toda tentativa de esquematização, em literatura, corre o risco de ser reducionista e equivocada - e o próprio autor acena para essa questão, ao notar a possibilidade de entrelaçamento entre as tendências e a complexificação do modelo quando se leva em conta não apenas o herói, mas também a ação e a ambientação romanescas. Entretanto, o segundo tipo proposto pelo crítico serve à discussão do romance regionalista na medida em que permite a análise da tensão entre o herói e a estrutura social em termos mais específicos e menos generalizantes: "o herói opõe-se e resiste agonicamente às pressões da natureza e do meio social, formule ou não em ideologias explícitas o seu mal-estar permanente". ${ }^{20}$

A tríade de personagens de Fogo morto, inserida na problemática da reestruturação da pirâmide social arquitetada pela monocultura açucareira no Nordeste e incorporando os movimentos de ascensão e decadência por meio de um esquema temporal que junta o declínio individual à falência coletiva, incorpora a tensão agônica em relação ao meio social e submete à sua composição narrativa outras instâncias que, em níveis distintos, operam a mesma resistência ao esmagamento. Tempo e espaço subordinam-se, portanto, ao eixo narrativo tripartido do romance, de modo que a perspectiva temporal que envolve os personagens José Amaro, Lula de Holanda e Vitorino Carneiro da Cunha e a esfera espacial ocupada por cada um deles regem, cada uma a seu modo, a mesma cadência trágica do homem levado ao limite da existência.

O "projeto ideológico" apontado por Lafetá na definição do romance de 30 estaria, assim, ligado a um modo de composição em que a crítica é incorporada à tessitura da narrativa. Essa relação dialética que faz do romance uma forma de absorção e expressão de valores - e, por extensão, de antivalores - pode servir mais amplamente à problematização do lugar ocupado pelo humor na prosa regionalista desse período, quando se leva em consideração a revisão do modelo, feita pelo próprio Alfredo Bosi, ${ }^{21}$ em texto mais recente. No ensaio "Narrativa e resistência", a dimensão crítica do romance é colocada em dois níveis, que podem ser estendidos à definição de dois tipos de narrativa: de um lado, a narrativa que tem a resistência como tema e, de outro, aquela em que a resistência se manifesta como processo imanente da escrita.

20. BOSI, Alfredo. História concisa da literatura brasileira. 35.ed. São Paulo: Cultrix, 1997. p.392.

21. BosI, Alfredo. "Narrativa e resistência". In: . Literatura e resistência. São Paulo: Companhia das Letras, 2002, pp. 118-35. 
Se a narrativa que toma a resistência como tema é circunscrita a um contexto de militância política, ${ }^{22}$ a narrativa de resistência imanente desvincula-se de determinações culturais e temporais específicas e, antes, permanece em consonância com um projeto estético de revelação de tensões e descontinuidades em que o indivíduo se posta aquém de uma estrutura social incapaz de o abrigar - o herói problemático à procura de valores em um espaço degradado, base do esquema interpretativo inicial, é aqui incorporado a uma estrutura mais complexa, em que a narrativa é tomada não apenas na relação entre sujeito e meio social, mas também na abrangência de suas instâncias.

Em sua linha mestra, o romance regionalista de 30 fundamenta-se em torno dessa narrativa, com traços de uma crítica lucidamente arranjada em composições em que a forma narrativa é, também, metonímia da ação social. A bagaceira, de José Américo de Almeida, e O quinze, de Rachel de Queiroz, são exemplares nesse sentido e revelam a natureza de um regionalismo menos tipificador - como aquele que se constituiu ao longo do pré-modernismo - e mais afinado a um projeto de constatação e crítica de diferentes aspectos da realidade local, enfocando homem e sociedade sob um olhar que articula o retrato à reflexão.

A caricatura do princípio do século é, portanto, suprimida por uma dimensão volumétrica em que não é mais possível inserir um tipo sem profundidade como o Jeca Tatu, de Monteiro Lobato: embora esse "regionalismo nordestino" tenha, em certa medida, partido de um paradigma de representação literária do sertanejo iniciado, em princípios do século $\mathrm{xx}$, com o caipira paulista, a forma analítica que adquiriu não poderia sustentar-se sobre os mesmos andaimes, já que também eles passaram a se apoiar em solo diverso. $\mathrm{O}$ processo de transformação da natureza do texto regionalista entre o pré-modernismo e a fase seguinte passa, portanto, pelo adensamento da forma romanesca, fomentadora da interpretação do indivíduo e da sociedade que o envolve, como discute Luiz Gonzaga Marchezan ${ }^{23}$ em análise da obra de Rachel de Queiroz:

[...] o romance, na ânsia de descrever uma situação, quer de uma sociedade, quer de um indivíduo, fixa-se na sua constituição (como também dissolução, decadência), com o

22. Alfredo Bosi restringe essa forma narrativa ao intervalo compreendido entre os anos 30 e 50 , relacionando-a à escrita de resistência aos regimes totalitários.

23. Marchezan, Luiz Gonzaga. "As pontas do romanceiro de Rachel de Queiroz". Sentidos dos lugares, Encontro Regional da Abralic, 10, Rio de Janeiro: Abralic, 2005, p. 4. 
objetivo de inventariar, construir uma visão integral dos fundamentos daquela sociedade ou da intimidade daquele indivíduo.

Para que se realize como forma de tensão crítica ou incorpore a resistência em sua estrutura, o romance regionalista de 30 passa, inevitavelmente, pela exigência da verdade a que se refere a epígrafe desta reflexão: exigência que se transfigura em procura quando essa verdade é entendida não em sentido absoluto de transcendência ou metafísica, mas na necessidade de revelação de condições reais de existência, histórica e culturalmente determinadas:

Nos romances em que a tensão atingiu ao nível da crítica, os fatos assumem significação menos "ingênua" e servem para revelar as graves lesões que a vida em sociedade produz no tecido da pessoa humana: logram por isso alcançar uma densidade moral e uma verdade histórica muito mais profunda. ${ }^{24}$

Até esse momento, falou-se de um paradigma de representação que se fundamenta em uma concepção mimética de prosa, engajada na medida em que, ao se qualificar pelo adjetivo "social", articula-se a um referente da realidade e o explora de um ponto de vista crítico, com o intuito de revelar a relação entre o homem regional e o ambiente local, entendidos tanto sob seu aspecto geográfico quanto social. É fato que os ciclos de romance do Nordeste tiveram como espinha dorsal essa relação; entretanto, há que se relativizar certo determinismo sociológico impulsionador de uma abordagem em que o binômio homem/meio é menos dinâmico do que esquemático, o que leva Bernardo Élis a identificar nessa produção a composição de um tipo humano a que denomina "homem telúrico": "[...] nesse momento, o foco de visão literária vai incidir mais nas relações que aquele homem mantém com seu meio geográfico e nas condições socioeconômicas que plasmam, do que propriamente nele, em sua essência última". ${ }^{25}$

Se a literatura de José Lins do Rego se enquadra nesse esquema, como quer grande parte da crítica literária brasileira, não se pode, entretanto, deixar de analisar a natureza de seu regionalismo, quando colocado ao lado dessa reflexão de Bernardo Élis, em que a natureza humana do homem regional aparece subordinada à análise

\footnotetext{
24. Bosi, Alfredo. História concisa da literatura brasileira. cit., p. 393.

25. ÉLis, Bernardo. “Tendências regionalistas no modernismo". In: ÁvilA, Affonso. O modernismo. 2. ed. São Paulo: Perspectiva, 2002, p. 89 (grifos do autor).
} 
de determinações do espaço. A discussão a respeito de Fogo morto, desenvolvida até aqui, apontou para os aspectos da narrativa que incorporam as trajetórias de homens que não se enquadram em uma estrutura social decadente e ultrapassada, o que não deixa de inserir o texto nesse esquema de interpretação. Ocorre, por outro lado, que o romance de José Lins do Rego assume dimensão mais complexa e profunda ao incorporar dramas humanos que ultrapassam o nível da relação entre homem e meio ou da representação de um "tipo telúrico", como afirma Bernardo Élis.

Fogo morto promove, sob esse aspecto, um "deslocamento do eixo de gravidade da ficção do meio para o homem", ${ }^{6}$ o que significa dizer que há um redimensionamento do foco de representação da realidade pela narrativa. Essa alteração de perspectiva ou, mais precisamente, a impregnação de uma perspectiva por outra representa, ainda, a transfiguração na natureza do regionalismo de que se reveste o romance de 1943: colocando o homem em primeiro plano, José Lins do Rego antecipa parte da universalização da prosa regionalista, levada às últimas consequências por seus sucessores.

Chega-se, portanto, a uma encruzilhada: embora Fogo morto esteja, em certa medida, de acordo com traços do paradigma regionalista de 30 - a que seu autor se liga desde a aproximação com Gilberto Freyre, na criação do Centro Regionalista -, há uma transformação no modo de representação que faz com que o romance transcenda o que, já em princípios da década de 1940 do século xx, existia de inflexível e esquemático no modelo. Não se pode negar que já em Banguê, de 1934, e Usina, de 1936, há uma dimensão psicológica que verticaliza o enfoque das relações e confere volume aos personagens; entretanto, é na arquitetura de Fogo morto que se tem a forma mais bem realizada de subjetivação do relato, de modo que a pluralização do foco narrativo e a temporalização permanente do espaço colocam o homem no centro da narrativa, projetando a decadência à esfera trágica da decrepitude humana.

Juliana Santini é professora de literatura brasileira da UNESP, em Araraquara.

26. Coutinho, Eduardo F. “A relação arte/realidade em Fogo morto”. In: Coutinho, Eduardo F.; CAsTro, Ângela Bezerra de (Orgs.). José Lins do Rego. Rio de Janeiro: Civilização Brasileira; João Pessoa: Funesc, 1991. p. 431. 